\title{
Characteristics of attenders and non-attenders at an asthma education programme
}

\author{
R Yoon, D K McKenzie, D A Miles, A Bauman
}

\begin{abstract}
Background A controlled trial of asthma education was conducted but only 51 out of 164 eligible patients participated.

Methods Differences between subjects who participated in the trial and those who expressed initial interest but subsequently declined were studied.

Results Women, non-smokers, and those whose attending physician was concerned in the study were significantly more likely to attend the programme. Higher socioeconomic status was associated with greater attendance, but this did not reach significance. Psychosocial malfunctioning due to asthma was also associated with attendance, but this was not significant when sex and education level were taken into account. There was no difference between attenders and nonattenders with respect to age, number of previous admissions, airway function, self reported asthma severity, knowledge about asthma, and self management practices.

Conclusion The results suggest that many asthmatic patients recovering from a severe exacerbation of airflow obstruction will not participate in hospital based health education programmes. Alternative strategies may be required to improve the self management behaviour of these patients.
\end{abstract}

Asthma affects about $16 \%$ of children ${ }^{1}$ and up to $10 \%$ of adults ${ }^{2}$ in Australia and hence has important social and economic consequences. Over the past 15 years treatment of asthma and its underlying inflammation has improved but the mortality associated with asthma seems to be increasing in several countries. ${ }^{2-10}$ The severity of and morbidity associated with asthma may also be increasing. " Potentially preventable factors have contributed to mortality from asthma in $60-80 \%$ of the cases reviewed ${ }^{512}$ and much morbidity may also be preventable. ${ }^{13}$ In the light of these findings it has been suggested that patient education may improve the management of asthma. ${ }^{1314}$

Various educational programmes for asthmatic patients have been shown to increase the knowledge and self management skills of participants, but the effect on long term morbidity has not been confirmed conclusively. ${ }^{15-18}$ A deficiency in most published studies of asthma educational programmes is the lack of information about attendance rates and whether the participants are representative of the target population. Attendance rates at asthma education programmes have ranged from $31 \%$ to $66 \%^{16-21}$ and were only 30 $40 \%$ in the two studies in which the true target population was estimated. ${ }^{20} 21$ None of these studies provided detailed analysis of the characteristics of attenders and non-attenders.

We examined the recruitment rate and attendance at an education programme among asthmatic patients admitted to hospital for an exacerbation of airflow obstruction. Questionnaire data and medical records were examined to compare a range of sociodemographic and medical characteristics in those who participated and those who declined.

\section{Methods}

An education programme for asthmatic patients was started in April 1987 at a large metropolitan teaching hospital. Over a period of 18 months one of the authors (RY) tried to recruit into the programme all patients admitted to the respiratory service for a severe exacerbation of airflow obstruction who satisfied the following criteria: were 16-65 years old, were literate in English, and had a diagnosis of asthma confirmed by history and documented reversibility of airflow obstruction. Patients with chronic airflow limitation were excluded if the attending physician considered that other factors (such as cigarette smoking) were largely responsible. Those with serious concurrent illnesses, those who lived too far from the education centre, and three women who were pregnant were also excluded. No records were kept of the numbers of patients who were excluded or who refused to participate at first contact and did not complete the questionnaire. Examination of medical records data for all admissions over the same period with asthma as the primary diagnosis on discharge enabled the total number of eligible patients to be estimated. Many patients were missed by the recruiting investigator because they were admitted to outlying wards or their stay was brief (for example, over a weekend).

The study was a cross sectional analysis of differences between the patients who subsequently attended the programme and those who were initially interested but did not participate. Subjects were informed at initial contact that the effectiveness of the education programme was to be assessed in a randomised controlled fashion with measurements at 
entry and at three and six months after the first assessment. Measures performed at each assessment included completion of a questionnaire, forced expiratory flow volume curves (Minato AS 500) before and after inhalation of a $\beta$ agonist (mean of two acceptable manoeuvres) and self monitored peak expiratory flows recorded before and after inhalation of a $\beta$ agonist in the morning and evening for seven days. The educational component was a single two and a half hour session for small groups aimed at improving knowledge, inhaler techniques, and the ability to control airflow obstruction through peak flow monitoring and appropriate use of maintenance therapy and a treatment plan. Intervention subjects received the educational component after the initial assessment while control subjects waited six months before receiving it. "Attenders" included both the intervention and the control subjects.

All asthmatic patients who expressed initial interest in the programme completed a baseline questionnaire while still in hospital. After discharge they were invited by letter and telephone to attend the education programme. Non-respondents were telephoned three to five times by the investigator who had made initial contact. Most eventual attenders either responded to the letter or required only one telephone call.

\section{DATA COLLECTION}

Sociodemographic variables (such as age, sex, postcode, marital status, occupation, and smoking status); medical history; length of hospital stay; and measurements of airway function on admission and at discharge were obtained from the patients' medical records retrospectively. Data obtained from the medical history included intercurrent illnesses and age of onset of asthma. Additional data were obtained from the baseline questionnaire to allow comparison of attenders and nonattenders. The questions were designed to provide measures of $(a)$ psychosocial disturbance due to asthma, (b) self reported frequency of asthma symptoms, (c) knowledge about asthma, and (d) aspects of self management behaviour appropriate to asthma control. Psychosocial disturbance was measured by using seven questions with responses scored on a four point Likert scale (which ranged from "very much applies to me" to "does not apply to me"), a high score indicating more psychosocial disturbance (modified from the method of Bauman et $a^{22}$ ). Asthma symptoms during the preceding six months were quantitated by using three questions about the frequency, duration, and severity of episodes of wheeze (each scored out of 3), a visual analogue scale of severity of asthma in the past six months (mild to severe, scored out of 4 ), and a physical activity scale (scored out of 4). ${ }^{23}$ Knowledge was measured by using one multiple choice question on asthma physiology and two open ended questions on judging the severity of asthma and the use of a crisis management plan. ${ }^{22}$ There were also five knowledge statements, each with five answers ranging from "strongly disagree" to "strongly agree" (scored as 0 for the three statements at the incorrect end of the scale to 2 and 4 for the options at the correct end; see appendix). Aspects of health behaviour were measured by using six statements scored with a 5 point Likert scale (appendix). A high score indicated desired or appropriate behaviour.

\section{ANALYSIS OF DATA}

Attenders and non-attenders at the asthma education programme were compared with respect to their responses to the baseline questionnaire, sociodemographic background, and airway function on admission and at discharge. Bivariate sociodemographic variables were compared by $\chi^{2}$ tests and continuous variables by Student's unpaired $t$ tests (for independent samples) after the distribution had been checked for normality. Statistical analysis was carried out by using the statistical package for social sciences (SPSS). Multivariate analysis, taking account of the interrelation between independent variables, was also carried out by using a stepwise logistic regression model from a statistical package (BMDP-LR). Whether the subject was an attender or a non-attender was the dichotomised dependent variable.

\section{Results}

Of 164 eligible patients, $120(73 \%)$ agreed to participate in the programme and completed a baseline questionnaire. Of these 120 patients, only $51(43 \%)$ completed the education programme and evaluation. This comprised only $31 \%$ of the eligible asthmatic patients. The 69 non-attenders who had completed a baseline questionnaire included eight who could not be contacted at the address or telephone number registered at the hospital, 10 who attended the initial evaluation for baseline lung function measurements and a further questionnaire but failed to return peak flow records or continue with the programme, and 51 who refused to attend when telephoned (after discharge) or failed to keep three or more appointments.

Data from the baseline questionnaire and from the medical record survey are presented together where relevant so that variables are grouped in a logical fashion.

\section{SOCIODEMOGRAPHIC CHARACTERISTICS}

Attenders and non-attenders did not differ significantly with respect to mean age ( 32 years, $95 \%$ confidence interval 28.9 to 34.9 years, $v 30$ years, $27 \cdot 1$ to 33.0 years). The mean age at which asthma was first diagnosed, however, was significantly lower in non-attenders (11 years, 7.4 to 14.6 years) than in attenders (17 years, 13.2 to 20.5 years; $p=0.028$ ). The table gives some of the sociodemographic data of the sample population. The attenders were similar to non-attenders with respect to the proportion with medical insurance and the number of previous hospital admissions. Two demographic variables - sex and level of educationwere significantly associated with attendance, 
Characteristics of the total sample $(n=120)$ and proportion of those who attended the programme $(n=51)$

\begin{tabular}{|c|c|c|c|}
\hline Variable & $\begin{array}{l}\text { Total sample } \\
\text { No }(\%)\end{array}$ & $\begin{array}{l}\text { Patients who } \\
\text { attended programme } \\
\text { No }(\%)\end{array}$ & Difference ${ }^{\star}$ \\
\hline $\begin{array}{l}\text { Male } \\
\text { Female }\end{array}$ & $\begin{array}{ll}48 & (40) \\
72 & (60)\end{array}$ & $\begin{array}{ll}14 & (29) \\
37 & (51)\end{array}$ & $p=0.026$ \\
\hline $\begin{array}{l}\text { Educationt: } \\
\text { School only } \\
\text { Further education }\end{array}$ & $\begin{array}{ll}80 & (71) \\
32 & (29)\end{array}$ & $\begin{array}{ll}28 & (35) \\
20 & (61)\end{array}$ & $p=0.015$ \\
\hline $\begin{array}{l}\text { Medical insurance: } \\
\text { Insured } \\
\text { Not insured }\end{array}$ & $\begin{array}{ll}49 & (41) \\
71 & (59)\end{array}$ & $\begin{array}{ll}25 & (51) \\
26 & (37)\end{array}$ & NS \\
\hline $\begin{array}{l}\text { Marital status: } \\
\text { Single } \\
\text { Married }\end{array}$ & $\begin{array}{ll}58 & (48) \\
51 & (43)\end{array}$ & $\begin{array}{ll}19 & (33) \\
27 & (53)\end{array}$ & $p=0.053$ \\
\hline $\begin{array}{l}\text { First admission: } \\
\text { Yes } \\
\text { No }\end{array}$ & $\begin{array}{ll}59 & (49) \\
61 & (51)\end{array}$ & $\begin{array}{ll}29 & (49) \\
22 & (36)\end{array}$ & NS \\
\hline $\begin{array}{l}\text { Regular smoker: } \\
\text { Yes } \\
\text { No }\end{array}$ & $\begin{array}{ll}28 & (26) \\
89 & (74)\end{array}$ & $\begin{array}{rr}5 & (16) \\
46 & (52)\end{array}$ & $\mathrm{p}=0.001$ \\
\hline $\begin{array}{l}\text { Doctor: } \ddagger \\
\text { Investigator } \\
\text { Other }\end{array}$ & $\begin{array}{ll}23 & (21) \\
88 & (79)\end{array}$ & $\begin{array}{ll}16 & (70) \\
31 & (35)\end{array}$ & $\mathrm{p}=0.006$ \\
\hline
\end{tabular}

*Comparison of attenders and non-attenders on categorical variables by $\chi^{2}$ test $=$ df $=1$.

† Some patients failed to respond to the question.

tThe pulmonary physician responsible for follow up treatment. Twenty patients were discharged with no recorded arrangements for specialist follow up.

with women and those educated beyond high school being more likely to attend. There were about equal numbers of married and single people in the total sample. Married patients were more likely than single patients to attend, but the difference was not quite significant. Few current smokers attended the education programme. Asthmatic patients under the care of one of us after discharge were more likely to attend than those followed up by other pulmonary specialists or by their family doctor.

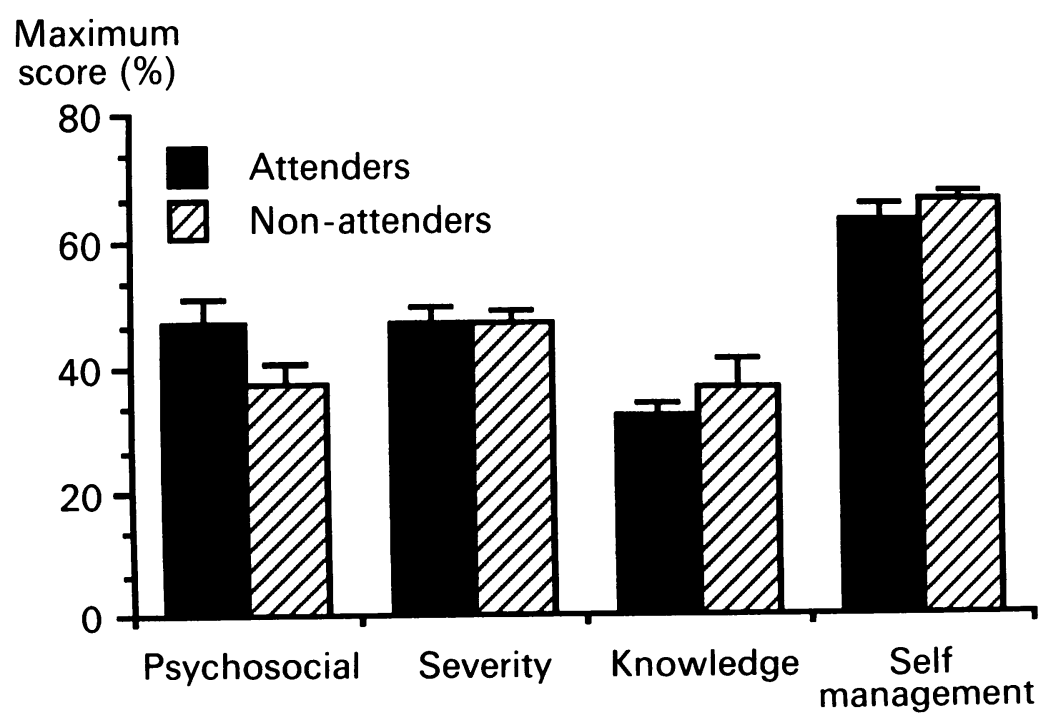

Mean ( $S E$ ) total scores for questions related to psychosocial disturbances attributable to asthma (a high score indicates more disturbance), severity of asthma, knowledge about asthma, and self management practices. For difference between attenders and nonattenders in psychosocial scores $p<0.05$.
PERCEPTIONS, KNOWLEDGE, AND HEALTH BEHAVIOUR

There were no significant differences between attenders and non-attenders with respect to any of the self reported measures of asthma severity, knowledge of asthma, or self management behaviour (figure). Knowledge about asthma was poor in both groups, with mean scores less than $35 \%$. Attenders reported more disturbance in psychosocial functioning due to asthma compared with non-attenders (that is, asthma affected their work, social, and recreational activities more and they expressed more feelings of anger and irritation about asthma; $p=0 \cdot 04$; figure).

\section{AIRWAY FUNCTION}

Spirometric variables were obtained from the medical records for 108 patients. The mean (SE) forced expiratory volume in one second $\left(\mathrm{FEV}_{1}\right)$ before treatment on admission was $25 \cdot 7$ $(1 \cdot 7) \%$ pred for attenders and $22 \cdot 2(1 \cdot 8) \%$ pred for non-attenders (not significant). At discharge after they had taken a bronchodilator the $\mathrm{FEV}_{1}$ was slightly higher in attenders than in nonattenders, but the difference did not reach significance $(83.6(3.7) \%$ pred $v 73.3(3.7) \%$ pred; $\mathrm{p}=0.52)$. There was no significant difference between the groups in the length of stay in hospital (attenders 7.0 (3.4) days, nonattenders $6 \cdot 2(3 \cdot 1)$ days).

\section{MULTIVARIATE ANALYSIS}

Three variables-smoking, sex, and attending physician-were independent predictors of attender status, after adjustment for other confounders. Women were twice as likely to attend as men (odds ratio $=2 \cdot 24,95 \%$ confidence interval 1.08 to 5.56 ), and smokers were only one third as likely to attend as nonsmokers $(0.38,0.15$ to 0.94$)$. Those whose attending physician was not one of us were one quarter as likely to attend $(0.23,0.09$ to 0.74$)$ as patients attended by one of us. Education level 8 was almost a significant predictor, with those who did not have tertiary qualifications less than half as likely to attend as those who did $(0 \cdot 49,0 \cdot 21$ to $1 \cdot 18)$.

\section{Discussion}

In this study despite conscientious efforts to recruit subjects only $31 \%$ of the estimated target population of eligible asthmatic patients

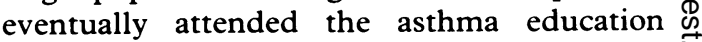
programme. Only $42 \%$ of the asthmatic 0 patients who expressed initial interest and $\overline{0}$ completed the baseline questionnaire even- $\stackrel{\mathbb{Q}}{\circ}$ tually attended. These figures are similar to $\mathbb{\mathbb { D }}$ those reported for an unselected series of patients treated in the emergency department of a North American hospital who were subsequently offered educational material about asthma $(31 \%){ }^{21}$ They are also comparable with the results of Clark et al, who reported the attendance of 232 children from a target population of 558 families with one or more eligible children. ${ }^{20}$

Information about attendance rates at diabetes and general health education 
programmes is also scarce. Community health projects which involve personal invitations and repeated efforts at recruitment generally achieve (partial or complete) attendance rates of less than $50 \%{ }^{24}{ }^{25}$ However, when recruitment relies on advertisements in the community attendance rates are much lower. One Scandinavian study reported a $2.5 \%$ attendance from the estimated target population after 12 months of advertising a general health promotion campaign. ${ }^{26}$

These results illustrate the difficulty of recruiting subjects to patient education programmes. The asthmatic patients approached in this study should have been highly motivated to obtain information and skills which might prevent further life threatening exacerbations of asthma. Nearly three quarters of the target population expressed interest and completed the baseline questionnaire during their admission. It is possible that interest waned with recovery or that the inclusion of evaluation measures and a controlled study design discouraged some patients. Financial and social considerations should not have influenced the decision to participate: the programme was free of cost and both the educational component and the evaluations were offered at various times (including after hours) and partners were encouraged to attend.

Determinants of attendance in this study included being female and a non-smoker. Those whose attending doctor was one of us were also more likely to attend. Socioeconomic status based on education level and medical insurance was almost a significant predictor. There was a clear trend for those with more psychosocial disturbance related to asthma to attend, but this variable was not an independent predictor after adjustment for other variables. This was almost certainly accounted for by the fact that the psychosocial score also correlated with female sex and with higher education level. Hilton et al ${ }^{16}$ found that attenders were more likely to report interference with daily activities from asthma, but they did not exclude confounding variables. ${ }^{16}$ They noted that young adults were less likely to attend but did not report the age of onset of asthma. In a limited analysis of differences between attenders and non-attenders at a paediatric programme Clarke et al found no significant differences apart from age-enrolled children were slightly younger than those whose care givers refused or could not be contacted. ${ }^{20}$ Many of the results are consistent with studies of general health promotion and reduction of cardiovascular risk factors. Attenders are more likely to be women and married (or to have children) with higher educational level or socioeconomic status or both. ${ }^{24}$ Knowledge and beliefs about health are not usually discriminating factors. ${ }^{25}$ Better general health, higher activity levels, and lower smoking rates among attenders were reported in a previous health promotion programme. ${ }^{26}$

The lower participation rate for men could not be accounted for by a higher level of current employment because those currently employed were, if anything, more likely to attend regard- less of sex, though the difference failed to reach significance.

The observation that attenders had slightly better airway function at discharge than nonattenders may reflect the finding that nonattenders included more smokers and more asthmatic patients with onset of asthma at a younger age, and may therefore have included more subjects with incomplete reversibility. ${ }^{28}$ The low attendance rate among patients whose asthma was of childhood onset may also reflect an erroneous view that a long association with a disease imparts knowledge and self management skills. That smokers tended not to participate is not surprising and consistent with findings from other health promotion programmes.

Several implications may be drawn from the study. Firstly, the potential influence of asthma education programmes on the population morbidity and mortality attributable to asthma may be small because of poor participation rates. The reported effectiveness and estimated cost benefits of such programmes reflect the outcome in a minority of subjects who may be motivated to complete the course and adopt the recommended changes to life style and health behaviour. The result show that despite every encouragement many patients at risk of asthma (patients with multiple previous admissions, smokers, patients with impaired lung function) do not attend education programmes. New strategies will have to be devised to improve self management in these patients.

This study was supported by the Asthma Foundation of New South Wales and a health service development grant from the Commonwealth Government of Australia. We thank Professor J J H Colebatch for his comments on the manuscript; and the staff of the medical records department for their assistance.

\section{Appendix}

Questionnaire measures of knowledge about asthma and about self management behaviour were assessed by the following questions scored on a 5 point Likert scale (responses were: strongly agree, moderately agree, neutral, disagree a little, strongly disagree).

\section{KNOWLEDGE}

(i) The best judge of severity (of asthma) is how badly you are wheezing.

(ii) Asthma medications become addictive if used for too long.

(iii) Asthma can be brought on by foods in the diet.

(iv) Your doctor can judge the severity of asthma by listening to your chest.

(v) Asthma medications lose their effect if used for a long time.

SELF MANAGEMENT BEHAVIOUR

(i) It is difficult for me to remember to take my medications regularly.

(ii) I feel confident dealing with my asthma during very bad attacks.

(iii) I don't like to use my puffers in public.

(iv) I often delay in calling for help when I have a severe attack of asthma.

(v) With asthma I must always follow my doctor's instructions or I'll get sick.

(vi) If I use my medications properly I can keep my asthma under control. 
1 Britton W, Sedgwick C, Woolcock AJ. Prevalence of allergy and asthma in Australian children [Abstract]. Aust $N Z J$ Med 1984;14:545.

2 National Health and Medical Research Council of Australia. Asthma in Australia. Strategies for reducing morbidity and mortality. (Report of NHMRC working party on asthma associated deaths.) Canberra: NHMRC, 1988.

3 Musk AW, Ryan GF, Perera DM, D'Zouza BPJ, Hockey RL, Hobbs MST. Mortality from asthma in Western Australia. Med J Aust 1987;147:423-7.

4 Sly RM. Increases in deaths from asthma. Ann Allergy 1984; 53:20-5.

5 Sears MR, Rea HH, Beaglehole R, et al. Asthma mortality in New Zealand: a two year national study. $N Z$ Med J 1985; 98:271-5.

6 Sears MR, Rea HH, Fenwick J, et al. Deaths from asthma in New Zealand. Arch Dis Child 1986;61:6-10.

7 Burney PGJ. Asthma mortality in England and Wales: evidence for a further increase, 1974-84. Lancet 1986;ii:323-6.

8 Stewart CJ, Nunn AJ. Are asthma mortality rates changing? Br J Dis Chest 1985;79:229-34.

9 Evans R, Mullally DI, Wilson RW, et al. National trends in the morbidity and mortality of asthma in the USA: prevalence, hospitalisation, and death from asthma over two decades: 1965-1984. Chest 1987;91:65-74S.

10 Sly RM. Mortality from asthma, 1979-1984. J Allergy Clin Immunol 1988;82:705-17.

11 Baldwin DR, Ormerod LP, Mackay AD, Stableforth DE. Changes in hospital mangement of acute severe asthma by thoracic and general physicians in Birmingham and Manchester during 1978 and 1985. Thorax 1990;45:130-4.

12 British Thoracic Society. Death from asthma in two regions of England. $B M J 1982 ; 285: 1251-5$.

13 Sutherland DC. Asthma. Preventing hospital admission. Current Therapeutics 1984;25:39-46.

14 Parker SR, Mellins RB, Sogn DD. NHLBI Summary. Asthma education: a national strategy. Am Rev Respir Dis 1989;140:848-53.

15 Hindi-Alexander MC, Cropp GJA. Evaluation of a family asthma program. J Allergy Clin Immunol 1984;74:505-10.

16 Hilton S, Sibbald B, Anderson HR, Freeling P. Controlled evaluation of the effects of patient education on asthma morbidity in general practice. Lancet 1986;i:26-9.

17 Howland J, Bauchner $\mathrm{H}$, Adair R. The impact of paediatric asthma education on morbidity. Assessing the evidence. Chest 1988;94:964-9.

18 Clark NM. Asthma self-management education. Research and implications for clinical practice. Chest 1989;95: 1110-3.

19 Lewis CE, Rachelefsky G, Lewis MA, de la Sota A, Kaplan M. A randomised trial of A.C.T. (Asthma Care Training) for kids. Pediatrics 1984;74:478-86.

20 Clark NM, Feldman CH, Evans D, Levison MJ, Wasilewski $\mathrm{Y}$, Mellins RB. The impact of health education on frequency and cost of health care use by low income children with asthma. J Allergy Clin Immunol 1986; 78:108-15.

21 Bolton MB, Tilley BC, Kuder J. Are asthma patients receptive to education about their disease? [Abstract]. Clin Res 1988;36:909A.

22 Bauman AE, Craig AR, Dunsmore J, Browne G, Allen DH, Vandenberg $R$. Removing barriers to effective selfmanagement of Asthma. Patient Education and Counseling 1989;14:217-26.

23 McKenzie DK, Gandevia SC. Strength and endurance of inspiratory, expiratory and limb muscles in asthmatic and control subjects. Am Rev Respir Dis 1986;134:999-1004.

24 Hollis JF, Sexton G, Connor SL, Calvin L, Pereira C, Matarazzo JD. The family heart dietary intervention program: community response and characteristics of joining and non-joining families. Prev Med 1984;13:276-85.

25 Kirscht JP, Kirscht JS, Rosenstock I. A test of interventions to increase adherence to hypertensive medical regimens. Health Educ $Q$ 1981;8:261-72.

26 Malmgren S, Andersson G. Who were reached by and participated in a one year newspaper health information campaign? Scand J Soc Med 1986;14:133-40.

27 Pirie PL, Elias WS, Wachman DB, et al. Characteristics of participants and non participants in a community cardiovascular disease risk factor screening: the Minnesota heart health program. Am J Prev Med 1986;2:20-5.

28 Martin AJ, Landau LI, Phelen PD. Asthma from childhood at age 21: The patient and his disease. $B M J$ 1982;284 $380-2$. 